\title{
Herpes zoster ophthalmicus followed by contralateral hemiparesis: report of two cases and review of literature
}

\author{
ELI RESHEF, ${ }^{*}$ STEPHEN B GREENBERG, ${ }^{*}$ JOSEPH JANKOVIC, $\dagger$ \\ From the Departments of Neurology, $\dagger$ Medicine, ${ }^{*}$ and Microbiology and Immunology, ${ }^{*}$ Baylor College of
Medicine, Houston, Texas
}

SUMMARY Two patients with herpes zoster ophthalmicus and contralateral hemiparesis are described, and their findings compared with 49 patients previously reported. These patients presented with delayed contralateral hemiparesis approximately seven weeks after the onset of herpes zoster ophthalmicus. Most patients had evidence of infarction of the ipsilateral middle cerebral artery by angiography or by CT scan. Cerebrospinal fluid pleocytosis and elevated protein commonly were found. Twenty per cent of the reported patients died, but they were older than the patients who survived and predisposed to have diffuse CNS lesions. The pathogenesis of this syndrome is thought to be due to direct viral invasion of the blood vessel wall with resulting angiitis. Further studies need to be performed to clarify the role of specific antiviral therapy or anti-inflammatory agents in treating this complication of herpes zoster.

Involvement of the ophthalmic branch of the trigeminal nerve by herpes zoster is often complicated by local spread to the eye, post-herpetic neuralgia, and a variety of neurological problems including cranial nerve palsies, meningoencephalitis, and, less commonly, contralateral hemiparesis. ${ }^{1-3}$ Although the first case of herpes zoster ophthalmicus followed by contralateral hemiparesis was described by Dumery in $1896,{ }^{4}$ this unusual complication has been reported with increasing frequency in the last few years. ${ }^{4-40}$ We have recently evaluated two cases of herpes zoster ophthalmicus followed by contralateral hemiparesis and have reviewed 49 other cases from published reports. The clinical presentation, patient characteristics, methods of diagnosis, and pathogenesis are discussed.

\section{Case reports}

CASE 1

A 42-year-old white male with a history of chronic renal failure was admitted in August, 1982 for evaluation of herpes zoster of the right ophthalmic branch. One year prior to admission, he underwent a second renal transplant

Address for reprint requests: Stephen B Greenberg, MD, Department of Medicine, Baylor College of Medicine, 1200 Moursund Avenue, Houston, Texas 77030, USA.

Received 31 May 1984. Accepted 14 July 1984 and was on azathioprine and prednisone at the time of admission. The patient received adenine arabinoside (Vid 8 arabine) $600 \mathrm{mg}$ intravenously but shortly thereafte developed a high fever, chills, nausea, and vomiting, and the medication was discontinued. At the time of discharge he complained of "double vision," and was found to have a right superior oblique palsy.

At home he became somnolent, increasingly depressed, and had memory lapses. Five days prior to his next admission and approximately 30 days after the onset of herpes zoster, he developed ataxia. On readmission, he was mildly somnolent. Ophthalmological examination revealed a right iritis. EEG showed diffuse slowing without lateralisation. CT scan of the head was normal. Over the next two weeks his mental status improved and he was discharged with pain medications and local eye care.

On the night of his third admission in late October 1982 , approximately ten weeks after the onset of his herpes zoster, he experienced sudden onset of left arm incoordination, drooping of the left corner of the mouth, numbness of the left side of the body, and left foot weakness. On admission, he was somnolent but oriented. Marked left face, arm and leg weakness was present. The deep tendon reflexes were normal, but there were bilateral plantar extensor responses. Except for hypoaesthesia in the distribution of the right ophthalmic branch of the trigeminal nerve, there were no sensory deficits. The CSF was clear with one red blood cell and two mononuclear cells $/ \mathrm{mm} .^{3} \mathrm{CSF}$ protein was $67 \mathrm{mg} / \mathrm{dl}$ and glucose $52 \mathrm{mg} / \mathrm{dl}$ (serum glucose $91 \mathrm{mg}$ / dl). CT scan on admission showed an area of lucency at the right caudate nucleus and four days later the lucency was 
more prominent, with additional areas of lucency in the posterior and anterior internal capsule on the right. EEG showed mild slowing without lateralisation.

There was gradual improvement in motor function, speech and right eye vision during the hospitalisation. His post-herpetic neuralgia responded transiently to imipramine and pain medications. He was discharged after two weeks with moderate left-sided weakness, moderate dysarthria, and mild diplopia. CT scan in January, 1983 showed resolution of the anterior internal capsule lesion, and in March, 1983, a CT scan was normal. He underwent neurectomy of the supra-orbital branch of the right trigeminal nerve in March of 1983 for intractable neuralgia. Histological examination of the specimen, which also contained a small artery, revealed normal tissue without evidence of inflammation.

\section{CASE 2}

A 62-year-old black male with chronic lymphocytic leukaemia of 2 years duration was admitted in July, 1978 for evaluation of herpes zoster of the right ophthalmic branch beginning 5 days prior to admission. Intermittent chemotherapy (Leukeran) was given over the preceding two years; the last course being two months prior to admission. On admission, vesicular lesions were seen in the distribution of the ophthalmic division of the right trigeminal nerve and on the right upper palate. Neurological examination was normal. Shortly after admission, the patient's temperature rose to $103^{\circ} \mathrm{F}$, and his white cell count was $57,000\left(99 \%\right.$ lymphocytes)/ $\mathrm{mm}^{3}$. Brain scan and CT scan were normal. CSF was obtained on the third hospital day and contained 38 white blood cells ( $41 \%$ polymorphonuclear, $59 \%$ mononuclear cells), protein of $141 \mathrm{mg} / \mathrm{dl}$, and glucose of $61 \mathrm{mg} / \mathrm{dl}$. On the third hospital day, papulovesicular lesions were noted on the trunk and extremities. Three days later, an incomplete right third cranial nerve palsy and complete right sixth cranial nerve palsy were noted. Lumbar puncture was repeated on the seventh hospital day and revealed 15 white blood cells (22\% polymorphonuclear, $78 \%$ mononuclear cells) and a protein of 62 $\mathrm{mg} / \mathrm{dl}$. Cell block for leukaemic cells was negative. On the final three days of hospitalisation, the patient was noted by his family to have intermittent confusion, but he was discharged after 23 days in hospital.

His second admission was approximately 12 weeks after the onset of herpes zoster ophthalmicus. Eight days prior to admission, he noted gradual onset of left-sided weakness. On admission, he was alert and oriented, with slightly dysarthric speech. A central left facial palsy and left sixth cranial palsy were present. He had a left hemiparesis and left homonymous hemianopsia. No papilloedema was observed. Laboratory studies on admission revealed a haematocrit of $24 \%$ and a haemoglobin of $7.3 \mathrm{~g} / \mathrm{dl}$. Because of an associated auto-immune haemolytic anaemia, he was begun on prednisone, $60 \mathrm{mg}$ per day, as well as Leukeran, 6-8 mg per day. Lumbar puncture on the third day of hospitalisation revealed 16 white blood cells $(89 \%$ mononuclear cells $) / \mathrm{mm}^{3}$ and a protein of $79 \mathrm{mg} / \mathrm{dl}$. CT scan showed a large area of lucency in the distribution of the right middle and posterior cerebral arteries. Two days later the patient became lethargic and at that time the CT scan showed mass effect with a shift to the left. Dysart- hria and left central facial palsy improved, but hemiparesis persisted. Because the auto-immune haemolytic anaemia was poorly controlled the daily dose of prednisone was increased to $100 \mathrm{mg}$. On the twenty-second hospital day, he became febrile and markedly lethargic. He had Cheyne-Stokes respirations, small unreactive pupils, and bilateral plantar extensor response. CT scan was compatible with uncal herniation. After receiving intravenous mannitol he became alert. The prednisone was reduced to $35 \mathrm{mg}$ a day and after a course of Leukeran, the autoimmune anaemia stabilised and he was discharged five weeks later.

\section{Review of literature}

Fifty-one cases for which there is adequate information are included in our review. ${ }^{4-40}$ However, several other patients are not included because of the limited information that was provided. ${ }^{41}{ }^{42}$ The mean age of the reported patients with herpes zoster ophthalmicus-contralateral hemiparesis was 58.1 years with a range of seven to 96 years (table). The mean age among the women was 62.5 , and among men 54.6 . More than $75 \%$ of the patients were between the ages of 40 to 75 years. There were 29 men and 22 women. The average interval between the onset of herpes zoster ophthalmicus and that of contralateral hemiparesis was $7 \cdot 3$ weeks, with a range of one week to six months. Thirty patients had herpes zoster ophthalmicus on the left side and 21 on the right. Only 14 patients (28\%) had an underlying condition: six were undergoing or recently had undergone chemotherapy for maligancies (lymphosarcoma, prostatic cancer, chronic lymphatic leukaemia ( 2 patients), breast cancer, and colon cancer); eight had noncancerous conditions (renal failure, rheumatoid arthritis, chronic alcoholism, diabetes mellitus, pancreatitis, myasthenia gravis, and pulmonary sarcoidosis).

\section{Clinical course}

Twenty-four patients (47\%) exhibited diffuse CNS symptoms following the onset of herpes zoster ophthalmicus-fifteen at or following the onset of contralateral hemiparesis, nine prior to contralateral hemiparesis. These symptoms included stupor, somnolence, general disorientation, confusion, and/or memory deficits. Among the latter nine patients, three had disseminated zoster between the onset of herpes zoster ophthalmicus and contralateral hemiparesis. One patient had disseminated zoster without diffuse CNS symptoms prior to the onset of contralateral hemiparesis. Documented seizures were rarely recorded in these patients.

Ten patients $(20 \%)$ in this series died during or shortly after hospitalisation for contralateral hemiparesis; two had disseminated zoster. Nine of 
the ten who died had diffuse CNS symptoms during the course of their illness. One had chronic lymphatic leukaemia, one had lymphosarcoma, and one had breast cancer. Fifteen of the 16 patients with aphasia had herpes zoster ophthalmicus on the left side. Cerebellar signs were among the presenting symptoms in three patients.

\section{Cerebrospinal fuid findings}

The CSF, which was obtained from 40 patients, was abnormal in 28 patients during the course of their disease (table). The CSF was "normal" in 12 patients, but was obtained usually only once. Twenty-one patients had abnormal CSF at the onset of contralateral hemiparesis or shortly thereafter. Seven patients had abnormal CSF prior to the onset of contralateral hemiparesis. Of these seven, three had disseminated zoster prior to contralateral hemiparesis (two died), the four others had diffuse CNS symptoms prior to contralateral hemiparesis. Typically, the CSF had elevated white blood cells (range $0-1200$ ), elevated protein (range 48 to 445 $\mathrm{mg} / \mathrm{dl}$ ), and normal levels of glucose. Mononuclear cells predominated. One patient ${ }^{28}$ reportedly had 1200 polymorphonuclear leucocytes $/ \mathrm{mm}^{3}$. Hypoglycorrhachia was reported in only two patients.

\section{Radiographic studies}

Angiograms were performed in 20 patients (table). Only one was interpreted as "normal" but was done ten months after herpes zoster ophthalmicus and in the early years of this procedure. Fifteen of the 19 abnormal angiograms showed ipsilateral segmental constrictions and dilatations or local stenosis or occlusion of the middle cerebral artery. Four showed involvement of the ipsilateral internal carotid artery, one with internal carotid artery aneurysm, five had involvement of the ipsilateral anterior cerebral artery, one had involvement of the ipsilateral posterior cerebral artery, and one had involvement of the contralateral anterior cerebral artery.

CT scans of the head were performed on 23 patients (table). Three were interpreted as "normal" but were not repeated after the onset of contralateral hemiparesis. Of the abnormal scans, three were normal at the onset of contralateral hemiparesis but later became abnormal. Seventeen were abnormal at the onset of contralateral hemiparesis. Ipsilateral involvement only was detected in 16 patients. Seven of those had infarcts at the internal capsule (posterior or anterior). The lesions in the remaining nine patients were described less specifically as "hemispheric," at the "distribution of the middle cerebral and posterior cerebral arteries," and in the occipital, frontal, or parietal lobe. Three patients had radiographic evidence of bilateral involvement-one with bilateral basal ganglia involvement, another with bilateral caudate lesions, and one with bifrontal lesions. One patient exhibited contralateral involvement (occipital lobe, 6.5 months after herpes zoster ophthalmicus).

Pathology

Histological examination was performed on speci-

Table Clinical characteristics, laboratory and non-invasive diagnostic studies in 51 patients with herpes zoster ophthalmicus and contralateral hemiparesis*

\begin{tabular}{|c|c|c|c|}
\hline & No. Abnormal/No. tested (\%) & Range & Mean \\
\hline \multicolumn{4}{|l|}{ Study population: } \\
\hline Age (years) & - & $7-96$ & $58 \cdot 1$ \\
\hline $\begin{array}{l}\text { Interval from herpes zoster ophthalmicus } \\
\text { to contralateral hemiparesis (wks.) }\end{array}$ & - & $1-24$ & $\begin{array}{r}50 \cdot 1 \\
7 \cdot 3\end{array}$ \\
\hline \multicolumn{4}{|l|}{ Clinical characteristics: } \\
\hline Aphasia & $16 / 51(31)$ & - & - \\
\hline Encephalopathy & $24 / 51(47)$ & - & - \\
\hline Underlying disease & $14 / 51(27)$ & - & - \\
\hline Death & $10 / 51(20)$ & - & - \\
\hline Laboratory results: & & & \\
\hline WBC & $26 / 31(84)$ & $0-1200$ & $46 \ddagger$ \\
\hline Protein & $22 / 38(58)$ & $30-445$ & 90 \\
\hline Glucose & $3 / 36(10)$ & $30-203$ & 68 \\
\hline Angiography§ & $19 / 20(95)$ & - & - \\
\hline CT Scan\| & $20 / 23(85)$ & - & - \\
\hline
\end{tabular}

*Besides our two patients, the other cases are reported from references 4-40.

† Most CSF samples were obtained at or shortly after onset of $\mathrm{CH}$.

¥In calculating the mean, one patient (ref. 28) has been omitted because of WBC of 1200 which were predominantly polymorphonuclear leucocytes. Differential white blood cell counts revealed predominantly mononuclear cells in most other cases. Normal CSF protein values are $14-45 \mu \mathrm{g} / \mathrm{dl}$. Normal CSF glucose values are $44-100 \mu \mathrm{g} / \mathrm{dl}$.

$\$ 15$ of 19 abnormal angiograms showed ipsilateral constrictions or occlusion of middle cerebral artery.

IIpsilateral findings in 16 of 20 tested. 
mens from fourteen patients, nine at necropsy, five via temporal artery biopsy or brain biopsy. Necrotising granulomatous angiitis of small and medium meningeal and cerebral arteries were a characteristic finding. ${ }^{2939}$ Ipsilateral cerebral infarcts were also documented in several patients. ${ }^{15182136}$

Temporal artery biopsies were performed in two patients. ${ }^{22}{ }^{30}$ The first, who had a palpable, tender temporal artery during the onset of contralateral hemiparesis, was found to have lymphocytic and plasmacytic infiltrate of all layers of the vessel, along with minimal intimal proliferation. Temporal artery biopsy in the other patient, however, revealed only arteriosclerosis. In one patient, ${ }^{34}$ temporal lobe and meningeal biopsies were performed and were normal. Temporal lobe biopsy in another patient ${ }^{38}$ revealed meningeal inflammation but no cerebral vasculitis or encephalitis. Occipital lobe biopsy in another patient ${ }^{37}$ was normal.

\section{Discussion}

Various mechanisms for the pathogenesis of herpes zoster ophthalmicus-contralateral hemiparesis have been proposed. Gordon and Tucker ${ }^{6}$ suggested the lesion was vascular in origin with a localised haemorrhage or destructive focus affecting the pyramidal tract. Cope and Jones ${ }^{8}$ believed that the contralateral hemiparesis was the result of direct invasion by the virus into the pyramidal tract. In 1959, Cravioto and Feigin ${ }^{43}$ provided the first description of a condition they termed "granulomatous angiitis of the CNS." They described the "proliferation of various mesenchymal cells in the intima, the adventitia, or in all layers of the vessel wall. Giant cells or foreign-body types were prominent." However, Kolodny et al ${ }^{15}$ provided the first description of herpes zoster ophthalmicus-contralateral hemiparesis with granulomatous angiitis of the CNS on necropsy. Rosenblum and Hadfield ${ }^{18}$ described another patient with herpes zoster ophthalmicuscontralateral hemiparesis and granulomatous angiitis. Both these last patients had disseminated herpes zoster prior to contralateral hemiparesis and a clinical picture of meningoencephalitis.

Linnemann and Alvira ${ }^{44}$ provided the first evidence for viral particles in the outer vessel walls in a patient who had herpes zoster ophthalmicus, disseminated herpes zoster, and meningoencephalitis with granulomatous angiitis at necropsy. They suggested that the granulomatous angiitis of the CNS resulted from direct viral invasion of blood vessels, perhaps by contiguous spread from cranial nerves. MacKenzie et al, ${ }^{32}$ proposed that virus spread, probably via vascular branches of the ophthalmic dis- tribution of the trigeminal nerve, was the likely pathogenesis. They described the characteristic angiographic findings in this condition.

Doyle et $a l,{ }^{36}$ found viral inclusion bodies in smooth muscle cells of cerebral vessels in a patient who died after herpes zoster ophthalmicuscontralateral hemiparesis. This patient, in contrast with the other patients ${ }^{15}{ }^{18}$ did not have disseminated herpes zoster, herpes zoster meningocencephalitis, or predisposing conditions for herpes zoster. The histologic findings were not those of granulomatous angiitis as classically described by Cravioto and Feigin. ${ }^{43}$ The involvement of the trigeminal ganglion, middle cerebral artery, and tributaries of the middle cerebral, anterior cerebral and basilar arteries, lend support to the proposition of direct viral spread along branches of the ophthalmic division of the trigeminal nerve to the arterial walls.

Clinically, there appears to be a continuum of cases of herpes zoster ophthalmicus-contralateral hemiparesis with "pure" herpes zoster ophthalmicus-contralateral hemiparesis on one end, and herpes zoster ophthalmicus-contralateral hemiparesis with meningoencephalitis on the other. It appears that different clinical variants of herpes zoster ophthalmicus-contralateral hemiparesis represent different degrees of cerebral vascular injury and not distinct, separate entities. Whether the histopathology of these extremes is different remains to be determined.

No proven treatment for herpes zoster ophthalmicus-contralateral hemiparesis has been described. Steroids and anticoagulants have been employed in treating some patients, but the published reports have demonstrated variable results. ${ }^{1220253236}$ Although recent studies with specific anti-herpes drugs have demonstrated efficacy in patients with uncomplicated varicellazoster infections, ${ }^{45-49}$ the potential benefit of these drugs in treating complications such as encephalitis or granulomatous angiitis is unknown. The apparent efficiency in limiting dissemination and complications with early anti-viral therapy in immunocompromised hosts suggest that these agents need to be tested in all patients with herpes zoster ophthalmicus because of the observed morbidity and mortality.

We thank Dr B Stinebaugh, Dr C Caplovitz, and Dr $S$ Dinerstein for allowing us to report their patients in this article. We thank Phyllis Faulkner for secretarial assistance.

\section{References}

' Marsh RJ, Dulley B, Kelly V. External ocular motor 
palsies in ophthalmic zoster: A review. Br J Ophthalmol 1977;61:667-82.

${ }^{2}$ Edgerton AE. Herpes zoster ophthalmicus: Report of cases and review of literature. Arch Ophthalmol $1945 ; 34: 40-62,114-53$.

${ }^{3}$ MacGillivray AG. Herpes zoster ophthalmicus and encephalitis. Br Med J 1931;2:895.

${ }^{4}$ Baudouin E, Lantuéjoul P. Les troubles moteurs dans le zona. Gazette des Hopitaux 1919;82:1293-5.

${ }^{5}$ Perrin M, Kissel P, Pierquin L, Gayet P. Hémiplégie post-zonateuse. Revue Medicale de Nancy 1938; 66:309-14.

- Gordon IRS, Tucker JF. Lesions of the central nervous system in herpes zoster. J Neurol Neurosurg Psychiatry 1945;8:40-6.

${ }^{7}$ Hughes WN. Herpes zoster of the right trigeminal nerve with left hemiplegia. Neurology (Minneap) 1951; 1: 167-9.

${ }^{8}$ Cope S, Jones AT. Hemiplegia complicating ophthalmic zoster. Lancet 1954;2:898-9.

${ }^{9}$ Deitz H. Periarteritis nodosa zosterica des Gehirnes mit Zoster Ophthalmicus. Nervenartz 1955;26:170-1.

${ }^{10}$ Minton J. A case of left herpes zoster ophthalmicus followed by virus encephalitis with right-sided anesthesia, paresthesia and hemiplegia. Trans Ophthalmol Soc UK 1956; 76:227-33.

"Anastasopoulos G, Routsonis K, Ierodiakonou CS. Ophthalmic herpes zoster with contralateral hemiplegia.J Neurol Neurosurg Psychiatry 1958;21:210-2.

${ }_{12}$ Laws HW. Herpes zoster ophthalmicus complicated by contralateral hemiplegia. Arch Ophthalmol 1960; 63:273-80.

${ }^{13}$ Acers TE. Herpes zoster ophthalmicus with contralateral hemiplegia. Arch Ophthalmol 1964;71:371-6.

${ }_{14}$ Pandi DN, Romanes GJ. Ophthalmological herpes zoster complicated by hemiplegia. Br J Ophthalmol 1966;50:610-1.

${ }^{15}$ Kolodny EH, Rebeiz JJ, Caviness VS, Richardson EP. Granulomatous angiitis of the central nervous system. Arch Neurol 1968;19:510-24.

${ }^{16}$ Norris FH, Leonards R, Calanchini PR, Calder CD. Herpes zoster meningoencephalitis. J Infect Dis 1970;122(4):335-8.

${ }^{17}$ Sato $\mathrm{M}$, Nabeyama T, Ikeda $\mathrm{H}$. A case of herpes zoster encephalitis complicated by sensory aphasia and contralateral hemiparesis. Rinsho Shinkeigaku 1971; 11:365-72.

${ }^{18}$ Rosenblum WI, Hadfield MG. Granulomatous angiitis of the nervous sytem in cases of herpes zoster and lymphosarcoma. Neurology (Minneap) 1972;22: 348-54.

${ }^{19}$ Walker RJ, Gammal T, Allen MB. Cranial arteritis associated with herpes zoster. Neuroradiology 1973;107:109-10.

${ }^{20}$ Gilbert GJ. Herpes zoster ophthalmicus and delayed contralateral hemiparesis. J Am Med Assoc 1974; 229(3):302-4.

${ }^{21}$ Rehurek J, Hanak L, Rehurkova M. Rare cerebral complications in herpes zoster ophthalmicus. Cs Oftal 1974;5:370-4.

22 Victor DI, Green WR. Temporal artery biopsy in herpes zoster ophthalmicus with delayed arteritis. Am J Oph- thalmol 1976;82(4):628-30.

${ }^{23}$ Nishimaru K, Kamei H. Herpes zoster ophthalmicus with contralateral hemiplegia. Rinsho Shinkeigaku 1976; 16:649-53.

${ }^{24}$ Gardner-Thorpe C, Foster JB, Barwick DD. Unusual manifestations of herpes zoster: A clinical and electrophysiological study. J Neurol Sci 1976;28:427-47.

${ }^{25}$ Pratesi R, Freemon FR, Lowry JL. Herpes zoster ophthalmicus with contralateral hemiplegia. Arch Neurol 1977;34:640-1.

${ }^{26}$ Sipe JC, Rosenberg JH. Granulomatous giant cell angiitis of the central nervous system-Neurological Clinicopathological Conference. University of California, San Diego, and San Diego Veterans Hospital (Specialty Conference). West J Med 1977;127:215-20.

${ }^{27}$ Onoda M, Takahashi A. Herpes zoster ophthalmicus followed by contralateral hemiparesis. Rinsho Shinkeigaku 1979;19:496-503.

${ }^{28}$ Gursoy G, Aktin E, Bahar S, Tolun R, Ozden B. Postherpetic aneurysm in the intrapetrosal portion of the internal carotid artery. Neuroradiology 1980;19: $279-82$.

${ }^{29}$ Ruppenthal M. Changes of central nervous system in herpes zoster. Acta Neuropathol (Berlin) 1980; 52:59-68.

${ }^{30}$ Landi G, Calloni MV, Scarlato G. Transient contralateral hemiplegia after ophthalmic zoster: Therapeutic problems in elderly patients. J Neurol 1981;

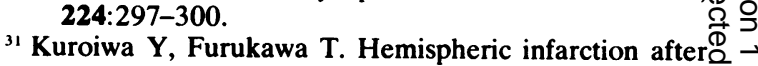
herpes zoster ophthalmicus: Computed tomography응 T and angiography. Neurology (NY) 1981;31:1030-2.

${ }^{32}$ Mackenzie RA, Forbes GS, Karnes WE. Angiographic findings in herpes zoster arteritis. Ann Neurol 1981;10(5):458-64.

${ }^{33}$ Vecht CJ, Sande JJ. Hemispheric infarction after herpes? zoster ophthalmicus (letter). Neurology (NY) 1982;32:914.

${ }^{34}$ McComas CF, Gutman L. Hemispheric infarction after herpes zoster ophthalmicus (letter). Neurology (NY) 1982;32:914-5.

${ }^{35}$ Federico F, Pedone D, Lamberti P, Achille P, Camicia M, Carella A, Ferrari E. Ophthalmic herpes zoster with contralateral hemiparesis: A case report. $J$ Neurol 1982;228:283-7.

${ }^{36}$ Doyle PW, Gibson G, Dolman CL. Herpes zoster ophthalmicus with contralateral hemiplegia: Identification of cause. Ann Neurol 1983;14:84-5.

${ }^{37}$ Menkes DB, Bishara SN, Corbett AJ. Hemispheric infarction after herpes zoster ophthalmicus. J Neurol Neurosurg Psychiatry 1983;46:786-8.

${ }^{38}$ Bourdette DN, Rosenberg NL, Yatsu FM. Herpes zoster ophthalmicus and delayed ipsilateral cerebral infarction. Neurology (NY) 1983;33:1428-32.

${ }^{34}$ Hilt DC, Buchholz D, Krumholz A, Weiss H, Wolinsky JS. Herpes zoster ophthalmicus and delayed contralateral hemiparesis caused by cerebral angiitis: diagnosis and management approaches. Ann Neurol 1983; 14(5):543-53.

${ }^{40}$ Elble RJ. Intracerebral hemorrhage with herpes zoster ophthalmicus. Ann Neurol 1983;14(5):591-2. 
${ }^{41}$ Womack LW, Liesegang TJ. Complications of herpes zoster ophthalmicus. Arch Ophthalmol 1983;101:42-5.

${ }^{42}$ Lightman S, Marsh RJ, Powell D. Herpes zoster ophthalmicus: A medical review. $\mathrm{Br} J$ Ophthalmol 1981;65:539-41.

${ }^{43}$ Cravioto H, Feigin I. Noninfectious granulomatous angiitis with a predilection for the nervous system. Neurology (Minneap) 1959;9:599-609.

${ }^{44}$ Linnemann CC, Alvira MM. Pathogenesis of varicellazoster angiitis in the CNS. Arch Neurol 1980;37:239-40.

${ }^{45}$ Whitley RJ, Ch'ien LT, Dolin R, Galasso GJ, Alford CA. Adenine arabinoside therapy of herpes zoster in the immunosuppressed. $N$ Engl J Med 1976;
294:1193-9.

${ }^{46}$ Whitley RJ, Soong SJ, Dolin R, Betts R, Linnemann C, Alford CA. Early vidarabine therapy to control the complications of herpes zoster in immunosuppressed patients. N Engl J Med 1982;397:971-5.

${ }^{47}$ Esmann V, Ispen J, Peterlund NA, Seyer-Hansen K, Schonheyder H, Juhl H. Therpay of acute herpes zoster with acyclovir in the non-immunocompromised host. Am J Med 1982;73: (Suppl) 320-5.

${ }^{48}$ Schulthess GK, Sauter C. Acyclovir and herpes zoster. $N$ Engl J Med 1981;305:1349.

${ }^{49}$ Selby PJ, Powles RL, Jameson B, et al. Parenteral acyclovir therapy for herpes virus infections in man. Lancet 1979;2:1267-70. 